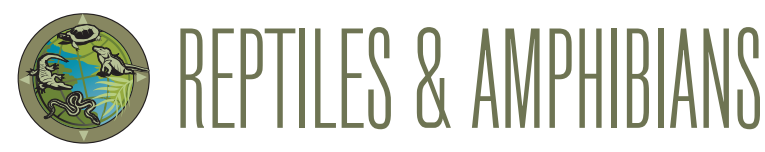

\title{
First Record of Dobson's \\ Burrowing Frog, Sphaerotheca dobsonii (Boulenger 1882), from The Dangs District, Gujarat, India
}

Dikansh S. Parmar

Department of Zoology, Goa University, Taleigao Plateau, Goa, India (ophiophagus_hannah10@yahoo.com)

$\mathrm{D}$ obson's Burrowing Frog (Sphaerotheca dobsonii) is a medium-sized fossorial dicroglossid found in the "Western Ghats of southern India (Maharashtra, Karnataka), and with substantially less confidence to the east and north to Andhra Pradesh and Orissa state" (Frost 2021). Most reports (e.g., Dutta 1997; Chanda 2002; Daniels 2005; Dinesh et al. 2009; Subramanian et al. 2013; Dahanukar et al. 2017; Prasad et al. 2019) list $S$. dobsonii from the Western Ghats; records from Orissa, Andhra Pradesh, and Tamil Nadu are in Dutta (1998), Daniels (2005), Srinivasulu and Das (2008), and Dinesh et al. (2009). Khandla and Trivedi (2018) reported an observation of $S$. dobsonii in the vicinity of Jamnagar City, Gujarat, without providing any evidence to support that record. Herein I provide the first documented record of $S$. dobsonii from Gujarat (Fig. 1).

At 2320 h on 25 August 2018, I found a road-killed Sphaerotheca dobsonii (SVL $45 \mathrm{~mm}$ ) on a roadside in The Dangs District, Gujarat $\left(20.7834519^{\circ} \mathrm{N}, 73.7141871^{\circ} \mathrm{E}\right.$; elev. $410 \mathrm{~m}$ asl) (Fig. 2). Morphometrics and morphological data (in particular the relative lengths of fingers, shape and size of the metatarsal tubercles, and the extent of webbing between the toes) were similar to descriptions in the literature. The specimen was deposited in the Bombay Natural History Museum, Mumbai, India (BNHS 6137); the identity of the species was confirmed by Dr. R.J. Ranjit Daniels, Care Earth Trust, Chennai, India.

Dahanukar et al. (2017) and Prasad et al. (2019) doubted that the range of the $S$. dobsonii would extend beyond the Western Ghats, which was reflected in the quote from Frost (2021) cited above. The northernmost extent of the Western Ghats ranges into The Dangs District in southern Gujarat, hence the possibility of $S$. dobsonii occurring there is reasonable. However, Jamnagar District is located across the Gulf of Khambhat in extreme northwestern Gujarat, rendering the unverified observation recorded by Khandla and Trivedi (2018) unlikely. Extensive surveys in Surat District (Parmar and Tank 2019), which is slightly north of The Dangs District, found no evidence of Dobson's Burrowing Frogs. However, the presence of an isolated population in extreme northwestern Gujarat remains a possibility in need of confirmation.

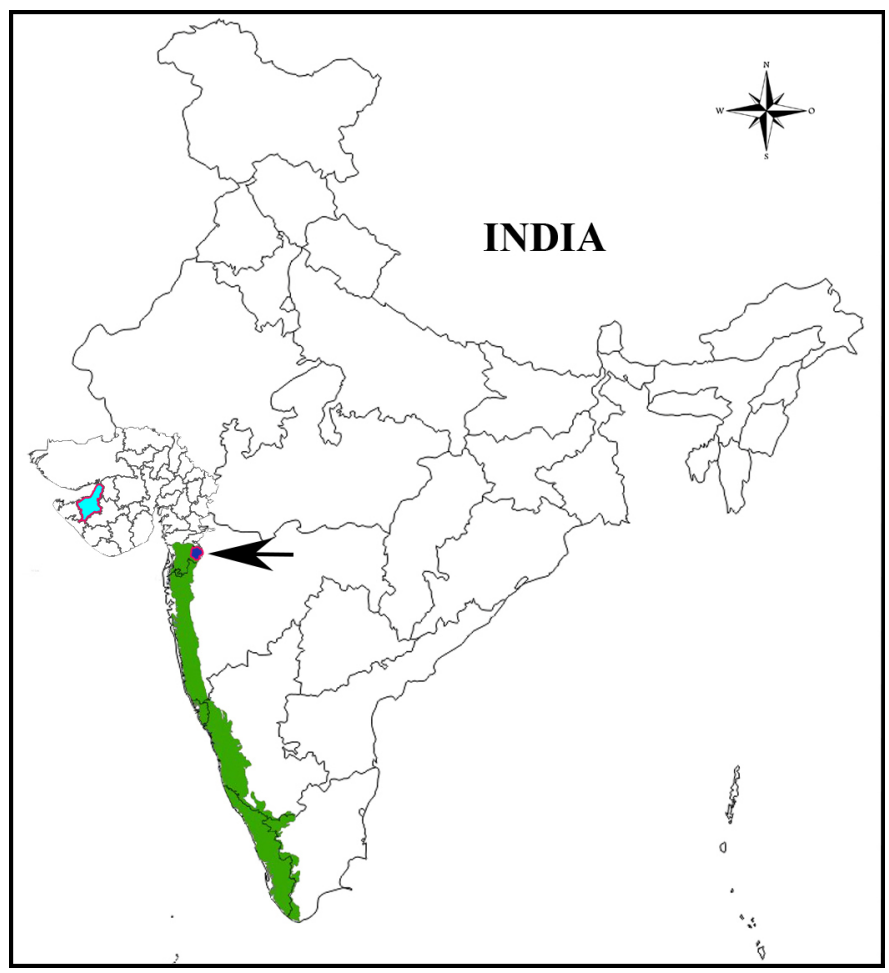

Fig. 1. Map of India showing the extent of the Western Ghats (green), the location of the new locality record for Dobson's Burrowing Frog (Sphaerotheca dobsonii) in The Dangs District, Gujarat (dark blue and marked by the arrow), and the unlikely record in Jamnagar District (light blue). 


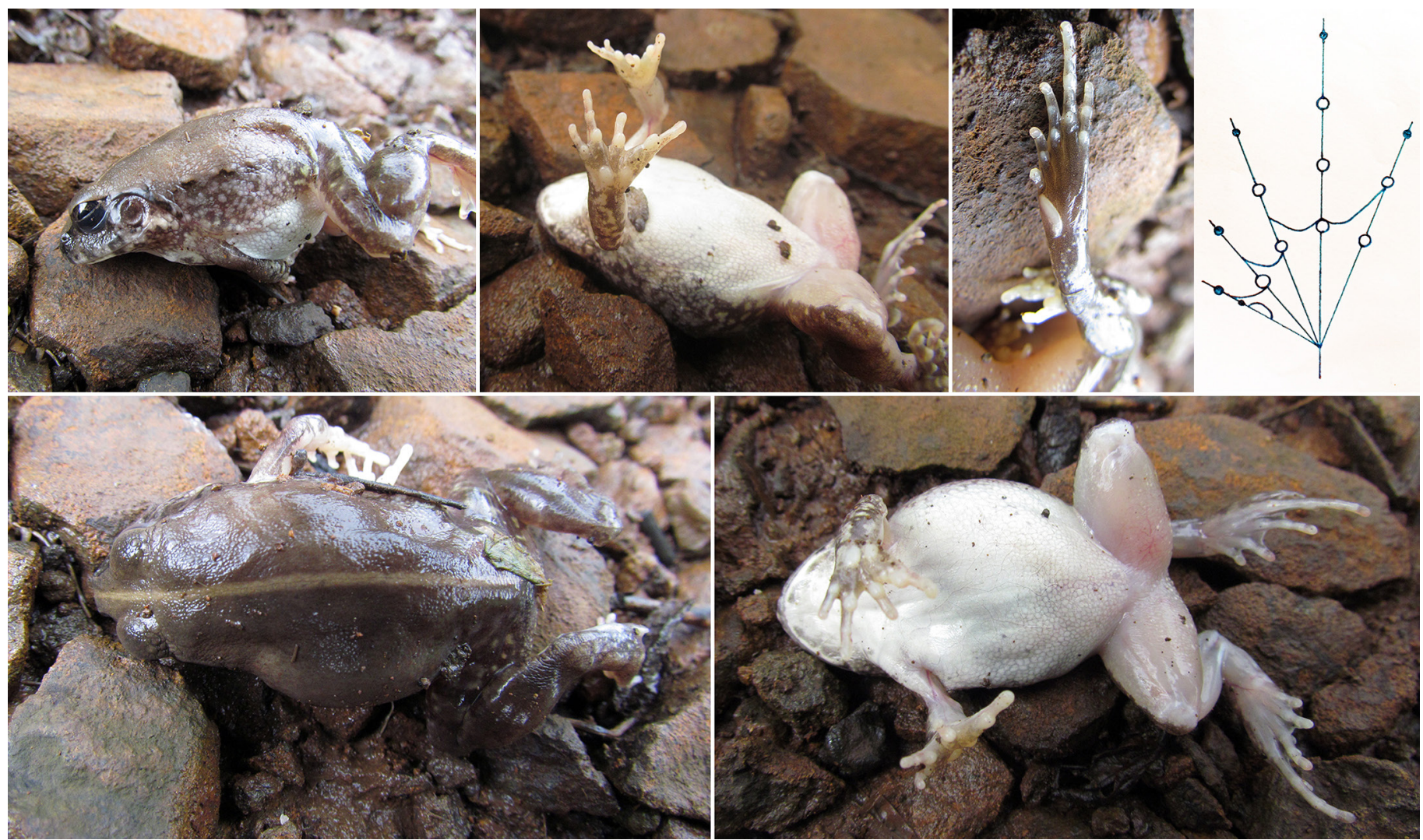

Fig. 2. A Road-killed Dobson’s Burrowing Frog (Sphaerotheca dobsonii) from The Dangs District, Gujarat, India. Note relative finger lengths (top center) and the metatarsal tubercle and extent of webbing on the toes (upper right). Photographs by D.S. Parmar; drawing by Vasudev Limbachiya.

\section{Acknowledgements}

I thank Divyesh G. Gamit, Manu Anand, and Piyush P. Kumar for logistic support; Vrajesh D. Patel for preparing the map; and Vasudev P. Limbachiya for the drawing in Fig. 4.

\section{Literature Cited}

Chanda, S.K. 2002. Handbook. Indian Amphibians. Zoological Survey of India, Calcutta, India.

Dahanukar, N., S. Sulakhe, and A. Padhye. 2017. Identity of Sphaerotheca pluvialis (Jerdon, 1853) and other available names among the burrowing frogs (Anura: Dicroglossidae) of South Asia. Journal of Threatened Taxa 9: 10269-10285. http://doi.org/10.11609/jott.3358.9.6.10269-10285.

Daniels, R.J.R. 2005. Amphibians of Peninsular India. University Press, Hyderabad, India.

Dinesh, K.P., C. Radhakrishnan, K.V. Gururaja, and G. Bhatta. 2009. An annotated checklist of Amphibia of India with some insights into the patterns of species discoveries, distribution, and endemism. Records of the Zoological Survey of India. Occasional Paper 302: [6] + 153 pp.

Dutta, S.K. 1997. Amphibians of India and Sri Lanka (Checklist and Bibliography). Odyssey Publishing House, Bhubaneswar, Orissa, India.

Dutta, S.K. 1998. First record of Tomopterna dobsoni (Boulenger, 1882) (Anura: Ranidae) from Orissa, India. Hamadryad 22: 117-118.
Frost, D.R. 2021. Amphibian Species of the World: An Online Reference. Version 6.1. American Museum of Natural History, New York, New York, USA. https://doi.org/10.5531/db.vz.0001. <https://amphibiansoftheworld.amnh. org/index.php>.

Khandla, Y. and V. Trivedi. 2018. A preliminary survey on anurans of Jamnagar City and vicinity areas, Gujarat, India. International Journal of Science and Research 7: 892-898.

Parmar, D. and S. Tank. 2019. Herpetofauna of Veer Narmad South Gujarat University, Surat, India. Reptiles \& Amphibians 26: 21-34. https://doi. org/10.17161/randa.v26i1.14324.

Prasad, V.K., K.P. Dinesh, A. Das, P. Swamy, A.D. Shinde, and J.B. Vishnu. 2019. A new species of Sphaerotheca Gunther, 1859 (Amphibia: Anura: Dicroglossidae) from the agroecosystems of Chota Nagpur Plateau, India. Records of the Zoological Survey of India 119: 197-210. https://doi. org/10.26515/rzsi/v119/i3/2019/132173.

Sreekumar, S. and K.P. Dinesh. 2020. Amphibians of agro-climatic zones of Maharashtra with an updated checklist for the state. Records of the Zoological Survey of India 120: 33-40. https://doi.org/10.26515/rzsi/v120/i1/2020/131811.

Srinivasulu, C. and I. Das. 2008. The herpetofauna of Nallamala Hills, Eastern Ghats, India: an annotated checklist, with remarks on nomenclature, taxonomy, habitat use, adaptive types, and biogeography. Asiatic Herpetological Research 11: 110-131.

Subramanian, K.A., K.P. Dinesh, and C. Radhakrishnan. 2013. Atlas of Endemic Amphibians of Western Ghats. Zoological Survey of India, Kolkata, India. 